\title{
Semibatch Surfactant-Free Emulsion Polymerization of Butyl Acrylate in the Presence of Carboxylic Monomers
}

\author{
Chorng-Shyan CHERN and Chi-Huei LiN \\ Department of Chemical Engineering, National Taiwan Institute of Technology, \\ Taipei, Taiwan 10672, Republic of China
}

(Received September 13, 1995)

\begin{abstract}
Incorporation of a small amount of acrylic acid (AA) into the polymer particles can depress the limited flocculation process and, therefore, result in a decrease in the particle size during the semibatch surfactant-free emulsion polymerization of butyl acrylate. The final latex particle size first increases to a maximum around $2 \% \mathrm{AA}$ and then decreases with increasing concentration of AA, which is due to the polyelectrolyte effect during the particle nucleation period. The final particle size increases significantly with increasing concentration of sodium bicarbonate (a neutralizing agent) because of the ionic strength effect. The run with the highest concentration of sodium bicarbonate shows the worst latex stability, whereas the run with $0.2 \%$ sodium bicarbonate leads to the best latex stability. The type of carboxylic monomers has an insignificant effect on the particle size. Both the $\mathrm{pH}$ and conductometric titration data suggest that a significant proportion of the AA unit is present near the particle surface layer, whereas the more hydrophobic methacrylic acid (MAA) unit can be distributed more uniformly in the particles. The critical flocculation conentration data show that incorporation of $5 \%$ AA or $5 \%$ MAA into the emulsion polymers can greatly improve the chemical stability of the finished latex products, especially when the $\mathrm{pH}$ is high. Furthermore, AA is more effective in promoting the chemical stability of the finished products as compared to MAA. KEY WORDS Emulsion Polymerization / Surfactant-Free / Semibatch / Latex Particles / Butyl Acrylate / Carboxylic Monomers / Latex Stability /
\end{abstract}

Semibatch emulsion polymerization ${ }^{1-17}$ is a process widely used to manufacture latex products because heat transfer in large scale reactors is rather limited. Furthermore, the semibatch process offers operational flexibility to produce latex products with controlled composition and morphology. The latex product is a dispersion of a large number of polymer particles ( $c a .50-1000 \mathrm{~nm}$ in diameter) in water. These submicron particles can collide with one another frequently and they tend to aggregate due to the attractive van der Waals force. Stability against coagulation can be achieved by addition of an anionic surfactant that imparts repulsive force between two similarly charged electric double layers to the emulsion polymer. Nevertheless, the surfactant present in the latex product can have a negative effect on the application properties of the coatings because the small and mobile surfactant molecules can easily migrate to the surface layer of the polymeric film.

One approach to overcome the surfactant contamination problem is to adopt the surfactant-free emulsion polymerization technique, ${ }^{16,18-25}$ in which only the sulfate end-group $\left(-\mathrm{SO}_{4}^{-}\right)$on the particle surface, derived from the persulfate initiator, is responsible for stabilization of the latex particles. Recently, Chern and $\operatorname{Lin}^{16}$ studied various reaction variables such as the total solids content, agitation speed, monomer feed rate, and concentrations of initiator and buffer on the semibatch surfactant-free emulsion polymerization of butyl acrylate (BA). The finished latex products with a target total solids content of $40 \%$ generally have very large particle sizes $(c a .500 \mathrm{~nm})$. Thus, sedimentation and agglomeration of the very large and soft poly(butyl acrylate) latex particles due to the gravitational force can be a problem during storage or transportation.

Furthermore, Chern and $\operatorname{Lin}^{16}$ have shown that the latex products produced by a surfactant-free technique can maintain an appreciable colloidal stability by the limited flocculation process during the reaction, especially at a higher total solids content. The limited flocculation process involves the growth of the latex particles by mild aggregation of a few particles in the course of polymerization. For example, the tremendous total particle surface area generated during the particle nucleation period can result in a lower particle surface charge density and, consequently, a lower potential energy barrier against flocculation. Therefore, the repulsive force among the interactive particles may not be high enough to keep these particles from flocculation. This action will in turn cause a decrease in the total particle surface area and, hence, increase the particle surface charge density. The flocculation process will diminish when the particle surface charge density increases to a critical level and most of the aggregated particles still can be stably dispersed in water. Such a limited flocculation process ${ }^{15,16,26,27}$ can make the task of particle size control more difficult.

Snuparek and Tutalkova ${ }^{9,10}$ studied semibatch emulsion polymerization of acrylic monomers. Their experimental data showed that only incorporation of a small amount of acrylic acid (AA) into the emulsion polymer improved the latex stability significantly. The ionized carboxyl group $\left(-\mathrm{COO}^{-}\right)$that is chemically incorporated into the emulsion polymer can increase the particle surface charge density and, therefore, enhance the repulsive force among the interactive particles. Recently, Chern and $\operatorname{Lin}^{17}$ studied the effects of different functional monomers such as acrylic acid (AA) and methacrylic acid (MAA) on the final latex particle size for semibatch emulsion polymerization of BA stabilized by a mixed surfactant system. The carboxylic monomer AA was found to be the most efficient one to help nucleate and stabilize the latex particles during polymerization. In addition, it was postulated that the aqueous phase reac- 
tion should play an important role during the particle nucleation period when the weight percentage of the carboxylic monomer in the monomer mixture was relatively high.

The objective of this work was to study the impact of incorporation of a small amount of carboxylic monomers (1-5\% AA or MAA based on total monomer) into the latex particles on the limited flocculation process, often encountered in the semibatch surfactant-free emulsion polymerization of pure BA. Another major thrust was to evaluate the possibility of preparing carboxylated poly(butyl acrylate) latices with a smaller particle size (e.g., $200-300 \mathrm{~nm}$ ). Furthermore, the resultant latex products will be characterized in order to gain a better understanding of the effect of the surfactant-free technique on their physical properties (e.g., the zeta potential, distribution of AA or MAA in the particles, and stability toward the added salt) as compared to the conventional emulsion polymerization system stabilized by surfactants.

\section{EXPERIMENTAL}

\section{Materials}

The chemicals used were butyl acrylate (Formosa Plastics Co.), acrylic acid (Formosa Plastics Co.), methacrylic acid (Mitsubishi Rayon), sodium persulfate (Riedelde-Haen), sodium bicarbonate (Nacalai Tesque, Inc.), sodium hydroxide (Riedel-de-Haen), hydrochloric acid (Nacalai Tesque, Inc.), sodium chloride (Riedel-deHaen), nitrogen, and deionized water (Barnsted, Nanopure Ultrapure Water System, specific conductance $<$ $0.057 \mu \mathrm{S} \mathrm{cm}^{-1}$ ). The primary monomer, butyl acrylate, was distilled under reduced pressure before use. All other chemicals were used as received.

\section{Polymerization Process}

Semibatch surfactant-free emulsion polymerization was carried out in a 1-1 glass reactor equipped with a 4bladed fan turbine agitator, a thermometer, and a reflux condenser. A typical recipe is shown in Table I. The total solid content was designed at $40 \%$ so that the latex product might be commercially viable. First, the initial reactor charge (water and sodium bicarbonate used as a neutralizing agent) was purged with nitrogen for $10 \mathrm{~min}$ to remove dissolved oxygen while heated to $80^{\circ} \mathrm{C}$, followed by addition of the initiator solution. The monomer mixture was then fed to the reactor over a prescribed period of time (e.g., $4 \mathrm{~h}$ for the experiment with a total

Table I. A typical recipe for semibatch surfactant-free emulsion polymerization of butyl acrylate/acrylic acid (95/5)

\begin{tabular}{lcc}
\hline & Chemicals & Weight $/ \mathrm{g}$ \\
\hline Monomer feed & $\mathrm{BA}$ & 212.5 \\
& $\mathrm{AA}$ & 11.2 \\
Initial reactor charge & $\mathrm{H}_{2} \mathrm{O}$ & 322.0 \\
& $\mathrm{NaHCO}_{3}$ & 0.66 \\
Initiator solution & $\mathrm{H}_{2} \mathrm{O}$ & 15.0 \\
& $\mathrm{Na}_{2} \mathrm{~S}_{2} \mathrm{O}_{8}$ & 0.65 \\
Total weight & & 562.0 \\
\hline
\end{tabular}

Theoretical total solids content $=40 \%$

Monomer feed rate $=0.93 \mathrm{~g} \mathrm{~min}^{-1}$ solids content of $40 \%$ ) by a FMI pump. The polymerization temperature was kept at $80^{\circ} \mathrm{C}$ throughout the reaction. After the end of the monomer feed, the reaction system was maintained at $80^{\circ} \mathrm{C}$ for $1 \mathrm{~h}$ to reduce the level of residual monomer. The total reaction time was $5 \mathrm{~h}$ in this work.

The finished latex product was filtered through a 40 -mesh $(0.42 \mathrm{~mm})$ and a 200 -mesh $(0.074 \mathrm{~mm})$ screen in series to collect the filterable solids. Scrap adhering to the agitator, thermometer, and reactor wall were also collected.

\section{Characterization of Carboxylated Latices}

Total solids content was determined by the gravimetric method. Particle size data were obtained from the dynamic light scattering method (Otsuka, Photal LPA$3000 / 3100)$. The zeta potential $(\zeta)$ of the latex particles was measured by Malvern's Zetamaster. For appropriate measurement, the finished latex product was diluted with water that had the same $\mathrm{pH}$ and conductivity as the original latex product. The $\mathrm{pH}$ and conductivity of the dilution water were adjusted by using $1 \mathrm{~N} \mathrm{HCl}, 0.5 \mathrm{~N}$ $\mathrm{NaOH}$, and $\mathrm{NaCl}$. Thus after dilution the latex particles were exposed to a similar aqueous environment as compared to the original. Five measurements were made for each sample and the average of these measurements was reported as the $\zeta$ of the finished product. On the other hand, in order to study the effect of ionic strength on the $\zeta$ of the final latex particles containing no carboxylic monomers, $5 \%$ AA, or $5 \%$ MAA, the sample was prepared by diluting the finished product $(0.05 \mathrm{ml})$ with $100 \mathrm{ml}$ water. The chemical $\mathrm{NaCl}$ was then used to adjust the ionic strength of the sample. Finally, the $\zeta$ of the final latex particles containing no carboxylic monomers, $5 \% \mathrm{AA}$, or $5 \%$ MAA as a function of $\mathrm{pH}$ was determined by the following procedure. The dialyzed latex product with a volume of $0.05 \mathrm{ml}$ was added to $100 \mathrm{ml} \mathrm{NaCl}$ solution. The total concentration of $\mathrm{NaCl}$ was kept constant $(0.01 \mathrm{M})$ in all these measurements. The sample was then allowed to stand at room temperature for $24 \mathrm{~h}$ before $\mathrm{pH}$ and $\zeta$ measurements.

For the latex product containing no carboxylic monomers, $5 \% \mathrm{AA}$, or 5\% MAA, both the $\mathrm{pH}$ titration and conductometric titration method ${ }^{28}$ were employed to study distribution of the carboxyl groups in the latex particles. The dialyzed latex product with a volume of $315 \mathrm{ml}$ and a solids content of $1.09 \%$ was titrated dropwise with $0.05 \mathrm{~N} \mathrm{NaOH}$ to study distribution of the carboxyl groups in the latex particles. Water-soluble oligomers containing carboxyl groups, if any, were assumed to be removed completely by dialysis (MWCO $\left.1.2 \times 10^{4}-1.4 \times 10^{4} \mathrm{~g} \mathrm{~mol}^{-1}\right)$. The latex sample was mixed thoroughly by a magnetic stirrer for $30 \mathrm{sec}$ and then it was allowed to stand at room temperature for $1 \mathrm{~min}$ before each $\mathrm{pH}$ measurement. The conductometric titration experiment was carried out by pouring the dialyzed latex product into $0.01 \mathrm{~N} \mathrm{NaOH}$ solution. The resultant sample had a volume of $315 \mathrm{ml}$ and a total solids content of $1.09 \%$. Changes in conductivity with time were then recorded by a conductivity meter (WTW, LF95/SET).

The transmittance of the dialyzed latex product (total solids content $=0.0128 \%$ ) was measured by a spectrophotometer (Metertek SP-810) at $540 \mathrm{~nm}$ for determina- 
tion of the critical flocculation concentration (CFC). The $\mathrm{pH}$ and ionic strength of the latex sample were adjusted by using $0.5 \mathrm{~N} \mathrm{NaOH}, 1 \mathrm{~N} \mathrm{HCl}$, and $\mathrm{NaCl}$. The sample was mixed thoroughly for $30 \mathrm{~min}$ and then it was allowed to stand at room temperature for $1 \mathrm{~h}$ before the transmittance measurement.

\section{RESULTS AND DISCUSSION}

\section{Effect of $A A$ Concentration}

In general, a small amount of carboxylic monomers, such as AA or MAA, can be incorporated into poly(butyl acrylate) latex particles to improve their colloidal stability and adhesion properties. Thus the carboxylic monomer AA, varied from $0 \%$ to $5 \%$ based on total monomer, was selected to study its effect on the semibatch surfactant-free emulsion polymerization of BA. Other parameters were kept constant in this series of experiments: the total solids content at the end of the reaction was $40 \%$, the agitation speed was $600 \mathrm{rpm}$, the monomer feed rate was $0.93 \mathrm{~g} \mathrm{~min}^{-1}$, and the concentration of the initiator and $\mathrm{NaHCO}_{3}$ was $0.19 \%$ and $0.20 \%$, respectively, based on total water.

Assuming that both nucleation of a second crop of primary particles (secondary nucleation) and coagulation did not take place during the monomer addition period, Chern and $\operatorname{Lin}^{16}$ used the following equation to predict the latex particle size $\left(d_{\mathrm{p}}\right)$ as a function of the reaction time after the start of the monomer feed $(t)$ :

$$
\begin{aligned}
& \log \left(d_{\mathrm{p}}\right)=1 / 3 \log (t) \\
& \quad+1 / 3 \log \left(6 W_{\mathrm{m}} /\left\{\pi t_{\mathrm{t}} N_{\mathrm{p}} V_{\mathrm{t}}\left[\rho_{\mathrm{m}}\left(1-\Phi_{\mathrm{p}}\right)+\rho_{\mathrm{p}} \Phi_{\mathrm{p}}\right]\right\}\right)
\end{aligned}
$$

where $W_{\mathrm{m}}$ is the total weight of monomer, $t_{\mathrm{t}}$ is the total monomer feed time, $N_{\mathrm{p}}$ is the number of particles per unit volume of the latex, $V_{\mathrm{t}}$ is the total volume of the finished product, $\rho_{\mathrm{m}}$ is the density of monomer, $\rho_{\mathrm{p}}$ is the density of polymer, and $\Phi_{\mathrm{p}}$ is the volume fraction of polymer in the particles. The ratio $t / t_{\mathrm{t}}$ represents the fraction of the monomer that has been added to the reactor. Thus, a plot of $\log \left(d_{\mathrm{p}}\right)-v s .-\log (t)$ should give a straight line with a slope of 0.333 if both the secondary nucleation and coagulation do not play an important role during polymerization.

The reproducibility of the finished latex products, prepared by the semibatch surfactant-free emulsion polymerization process employed in this work, has been shown to be reasonably good. ${ }^{16}$ Figure 1 shows the $\log \left(d_{\mathrm{p}}\right)-v s .-\log (t)$ data for the experiments with the weight percentage of AA in the monomer mixture ranging from $0 \%$ to $5 \%$. The experimental results are also compiled in Table II. The $d_{\mathrm{p}}$ data for the experiments containing no AA were taken from the work of Chern and Lin. ${ }^{16}$ For clarity, the $d_{\mathrm{p}}$ data were replaced by the average circular data points and vertical bars hereinafter. The dashed line represents the curve that passes through the average particle diameter data of the latices sampled at various

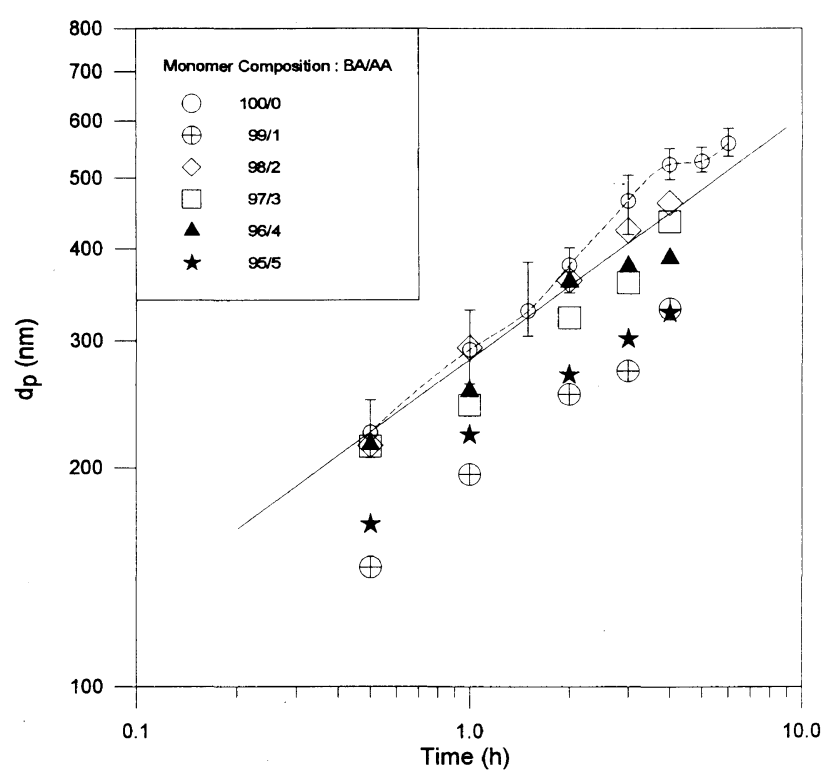

Figure 1. The latex particle size as a function of reaction time at various levels of acrylic acid. BA/AA: $(\bigcirc)$ 100/0; $(\oplus)$ 99/1; $(\diamond) 98 / 2$; ( $\square$ ) $97 / 3$; (A) $96 / 4$; ( $\star$ ) $95 / 5$.

Table II. Experimental data of the total amount of scrap, 200-mesh filterable solids, particle size, particle size distribution $\left(d_{\mathrm{w}} / d_{\mathrm{n}}\right)$, slope of the $\log \left(d_{\mathrm{p}}\right)-v s-\log (t)$ plot,

\begin{tabular}{|c|c|c|c|c|c|c|c|c|}
\hline & Total scrap & 200-mesh flocs & Particle size & & & & $\zeta$ & Yield \\
\hline & $\%$ & $\mathrm{ppm}$ & $\mathrm{nm}$ & & & & $\mathrm{mV}$ & $\%$ \\
\hline \multicolumn{9}{|l|}{$\mathrm{BA} / \mathrm{AA}$} \\
\hline $100 / 0$ & 0.14 & 39 & 561 & 1.10 & 0.383 & 7.9 & -100 & 94 \\
\hline $99 / 1$ & 0.87 & 20 & 321 & 1.08 & 0.374 & 4.4 & -81 & 90 \\
\hline $98 / 2$ & 1.27 & 81 & 512 & 1.08 & 0.365 & 4.0 & -75 & 89 \\
\hline $97 / 3$ & 0.19 & 32 & 427 & 1.20 & 0.336 & 3.9 & -66 & 91 \\
\hline $96 / 4$ & 0.37 & 105 & 401 & 1.28 & 0.308 & 3.8 & -55 & 87 \\
\hline $95 / 5$ & 0.19 & 40 & 327 & 1.10 & 0.317 & 3.8 & -53 & 91 \\
\hline \multicolumn{9}{|c|}{ BA/AA $(95 / 5)$} \\
\hline \multicolumn{9}{|c|}{$\left[\mathrm{NaHCO}_{3}\right](\%)$} \\
\hline 0.065 & 0.56 & 325 & 294 & 1.04 & 0.318 & 3.0 & -50 & 88 \\
\hline 0.20 & 0.19 & 40 & 327 & 1.10 & 0.317 & 3.8 & -53 & 91 \\
\hline 0.33 & 3.94 & 677 & 365 & $2.38^{\mathrm{b}}$ & 0.345 & 3.6 & -45 & 77 \\
\hline \multicolumn{9}{|c|}{$\mathrm{BA} / \mathrm{COOH}(95 / 5)$} \\
\hline AA & 0.19 & 40 & 327 & 1.10 & 0.317 & 3.8 & -53 & 91 \\
\hline MAA & 0.24 & 36 & 387 & 1.05 & 0.356 & 5.2 & -81 & 95 \\
\hline
\end{tabular}
zeta potential $(\zeta)$ of the finished products and yield

${ }^{\mathrm{a}} d_{\mathrm{w}} / d_{\mathrm{n}}$ is the polydispersity index of the particle size distribution. ${ }^{\mathrm{b}} \mathrm{A}$ bimodal particle size distribution. 
reaction times. On the other hand, the solid straight line with a slope of 0.333 represents the theoretical particlegrowth-pathway when both the secondary nucleation and coagulation are not operative during the reaction, as predicted by eq 1 . The $d_{\mathrm{p}}$ data for the experiments containing no AA deviate upward from the straight line with a slope of 0.333 . It has been postulated that in addition to conversion of the imbibed monomer to polymer in the latex particles, the particles also can grow via a limited flocculation process. As discussed above, the limited flocculation process can cause the relatively unstable, soft particles to aggregate together to reduce the total particle surface area and, consequently, increase the particle surface charge density. Thus the repulsive force among the interactive particles increases and the lightly aggregated latex particles can maintain an appreciable stability during polymerization.

It is shown in Figure 1 that incorporation of a small amount of AA into the poly(butyl acrylate) latex particles can cause a significant decrease in the particle size during the monomer addition period. The slope of the $\log \left(d_{\mathrm{p}}\right)-v s .-\log (t)$ plot decreases gradually from 0.383 to 0.317 when the concentration of $\mathrm{AA}$ is increased from $0 \%$ to $5 \%$, as shown by the least-squares-best-fitted slope data in Table III. The decreased deviation of the slope with $\mathrm{AA}$ is attributed to the enhanced latex stability (i.e., the retarded limited flocculation process) during the reaction. It is interesting to note that the slope is less than the predicted value $(0.333)$ for the runs with the AA concentration greater than $4 \%$. It is unlikely that secondary nucleation has occurred during the monomer feed period because the surfactant feed is not incorporated into the polymerization process. The $\log \left(d_{\mathrm{p}}\right)-v s \cdot-\log (t)$ plot that has a slope lower than 0.333 might be caused by coagulation of the larger particles of a normally distributed population because the shear-induced collision frequency is proportional to the cube of particle radius. This kind of action could shift the average particle size slightly toward the lower end. The particle size distributions of the finished latex products, as measured by the polydispersity index $d_{\mathrm{w}} / d_{\mathrm{n}}$, are relatively narrow (see Table II). Furthermore, the total amount of scrap and 200-mesh filterable solids data listed in Table II show that the carboxylated latices are relatively stable during the reaction. These findings suggest a method that can be used to produce a relatively clean poly(butyl acrylate)latex product with a smaller particle size ( $c a$. $300 \mathrm{~nm})$.

Figure 2 shows the $\log \left(d_{\mathrm{p}}\right)-v s .-\log [\mathrm{AA}]$ data at various reaction times, where $[\mathrm{AA}]$ represents the weight percentage of AA in the monomer mixture. The $d_{p}$ data of the latices sampled at the end of the monomer feed (see the square data points in Figure 2) do not follow the simple relationship: $d_{\mathrm{p}} \sim[\mathrm{AA}]^{n}$, where $n$ is a constant exponent. The parameter $d_{\mathrm{p}}$ first increases to a maximum around $2 \% \mathrm{AA}$ and then decreases with an increase in [AA]. This trend is consistent with the results obtained from a batch surfactant-free emulsion polymerization of styrene in the presence of a functional monomer sodium methallyl sulfonate ${ }^{23}$ and the work dealing with polyelectrolyte stabilized latices. ${ }^{29}$ This is because the amount of polyelectrolyte formed in water during the particle nucleation period will increase when $[\mathrm{AA}]$ is increased

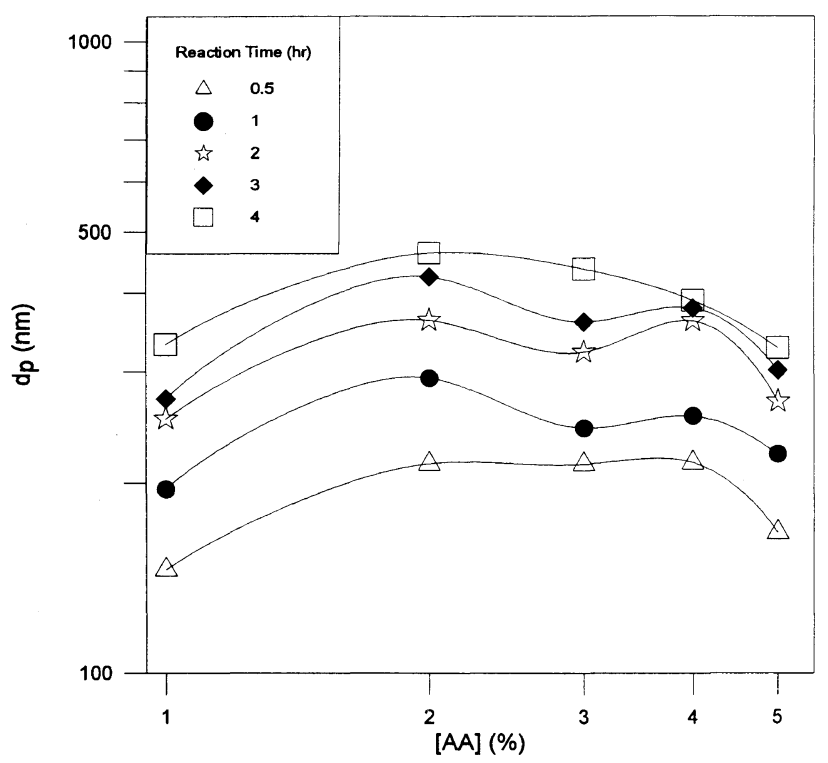

Figure 2. The latex particle size as a function of the weight percentage of AA in the monomer mixture at various reaction times: $(\triangle) 0.5 \mathrm{~h}$;

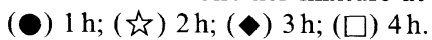

from $1 \%$ to $2 \%$. The ionized polyelectrolyte in the aqueous phase can compress the electric double layer of the nucleated primary particles and, hence, reduce the repulsive force among the interactive particles. This action can cause limited flocculation of the primary particles and thereby increase the final latex particle size. On the other hand, the probability of finding the polyelectrolyte adsorbed on the particle surface during nucleation will increase when [AA] is further increased from $2 \%$ to $5 \%$. In this case, the adsorbed polyelectrolyte can enhance the particle surface charge density and, consequently, increase the repulsive force among the interactive particles. The enhanced stability of the primary particles generated during the early stage of polymerization can result in a reduction in the final particle size.

In addition, both the $\mathrm{pH}$ and $\zeta$ of the finished latex product decrease with an increase in [AA] (see Table II). The very low $\mathrm{pH}$ (less than 5) of the finished product implies that not all of the carboxyl groups are in the dissociated (or ionized) state. The carboxylic monomer AA in an ionized form $\left(-\mathrm{COO}^{-}\right)$should be more effective in stabilizing the growing particles than that in the form of $-\mathrm{COOH}$ due to the electrostatic repulsion force provided by the negatively charged carboxyl groups on the particle surface. We then studied the effect of the concentration of the neutralizing agent $\left(\mathrm{NaHCO}_{3}\right)$ on the polymerization system containing 5\% AA.

\section{Effect of Sodium Bicarbonate Concentration}

In this series of experiments, the concentration of $\mathrm{NaHCO}_{3}$ was varied from $0.065 \%$ to $0.33 \%$. Other parameters were kept constant: the total solids content at the end of the reaction was $40 \%$, the agitation speed was $600 \mathrm{rpm}$, the monomer feed rate was $0.93 \mathrm{~g} \mathrm{~min}^{-1}$, the weight percentage of AA in the monomer mixture was $5 \%$, and the concentration of initiator was $0.19 \%$.

Figure 3 shows the $\log \left(d_{\mathrm{p}}\right)-v s$. $-\log (t)$ data for the experiments with various concentrations of $\mathrm{NaHCO}_{3}$. Please note that the curve with circular data points and error 


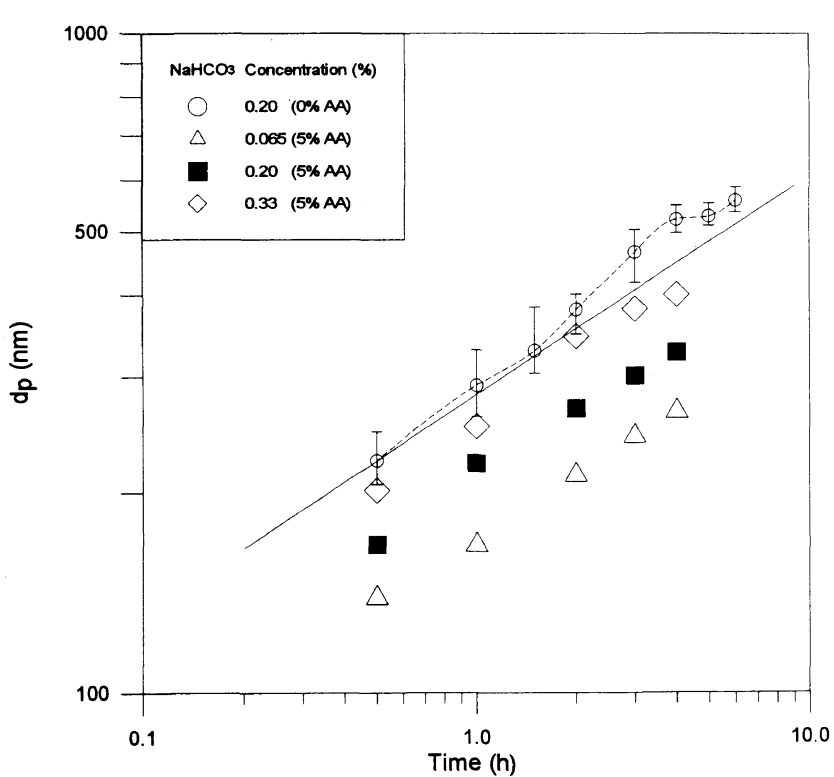

Figure 3. The latex particle size as a function of reaction time at various concentrations of sodium bicarbonate: $(\bigcirc) 0 \%$ AA, $0.20 \%$ $\mathrm{NaHCO}_{3} ;(\triangle) \quad 5 \%$ AA, $0.065 \% \quad \mathrm{NaHCO}_{3} ;$ (口) $5 \%$ AA, $0.20 \%$ $\mathrm{NaHCO}_{3} ;(\diamond) 5 \%$ AA, $0.33 \% \mathrm{NaHCO}_{3}$.

bars represents the $d_{\mathrm{p}}$ data for poly(butyl acrylate) latex containing no carboxylic monomers and it is included in this plot just for reference. It is interesting to note that the latex particle size increases significantly with an increase in the concentration of $\mathrm{NaHCO}_{3}\left(\left[\mathrm{NaHCO}_{3}\right]\right)$, probably due to the ionic strength effect. Although the degree of neutralization of the AA unit will increase with increasing $\left[\mathrm{NaHCO}_{3}\right]$, the electrolyte concentration will also increase correspondingly during the particle nucleation period. According to DLVO theory, ${ }^{30,31}$ the enhanced ionic strength can compress the electric double layer of the nucleated primary particles and, hence, reduce the repulsive force among the interactive particles. As discussed above, this kind of action can cause an increase in the extent of limited flocculation and thereby increase the particle size. This result is further supported by the total amount of scrap, 200-mesh filterable solids, and $d_{\mathrm{w}} / d_{\mathrm{n}}$ data shown in Table II. The run with the highest $\left[\mathrm{NaHCO}_{3}\right]$ shows the worst colloidal stability, whereas the run with $0.20 \% \mathrm{NaHCO}_{3}$ results in the best colloidal stability (see Table II). In addition, the $\zeta$ of the finished latex products are not very different $(-49 \pm 4 \mathrm{mV}$, see Table II), probably due to some kind of particle-size regulation mechanism provided by the limited flocculation process. In this series of experiments with $5 \%$ AA and various concentrations of $\mathrm{NaHCO}_{3}$, the slopes of the $\log \left(d_{\mathrm{p}}\right)-v s$. $-\log (t)$ data all center around 0.333 (see Table II).

\section{Effect of Type of Carboxylic Monomers}

Finally, the effect of the type of carboxylic monomers (5\% AA or $5 \%$ MAA) on the semibatch surfactant-free emulsion polymerization of BA was investigated in this series of experiments. Other parameters were kept constant: the total solids content at the end of the reaction was $40 \%$, the agitation speed was $600 \mathrm{rpm}$, the monomer feed rate was $0.93 \mathrm{~g} \mathrm{~min}^{-1}$, and the concentration of initiator and $\mathrm{NaHCO}_{3}$ was $0.19 \%$ and $0.20 \%$, respectively. The experimental results are presented below.

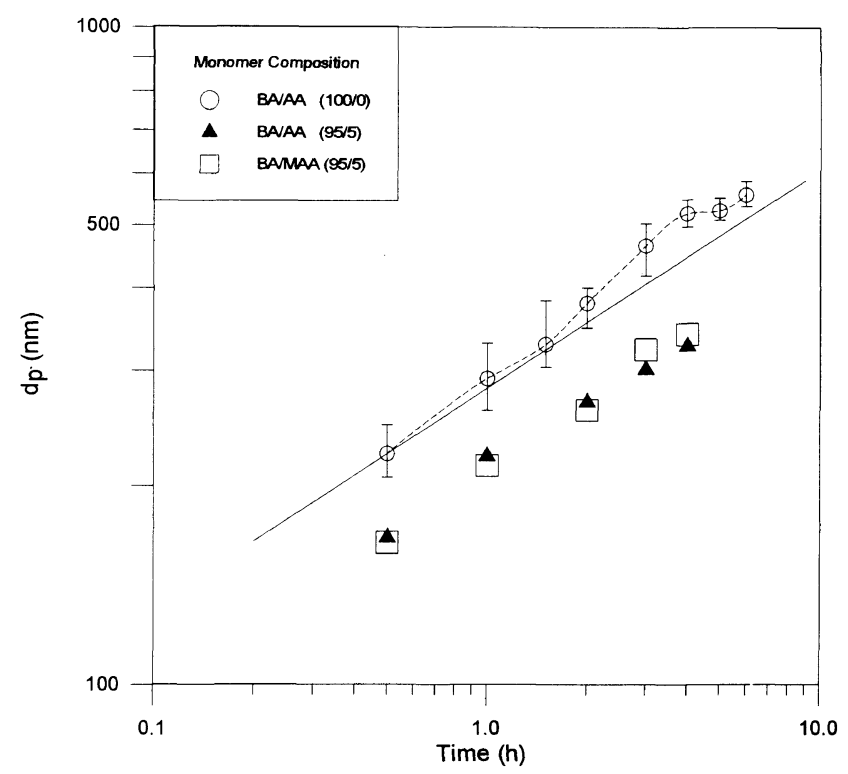

Figure 4. The latex particle size as a function of reaction time: $(O)$ BA/AA (100/0); (A) BA/AA $(95 / 5)$; ( $\square)$ BA/MAA $(95 / 5)$.

Ceska $^{19,20}$ studied batch surfactant-free emulsion copolymerization of styrene and a small amount of AA or MAA. He showed that the batch using MAA could nucleate more primary particles than the batch using AA. It was postulated that the carboxylic monomer MAA was more hydrophobic than AA. Thus, it was easier for MAA to diffuse to the surface layer of the primary particles and copolymerize with styrene thereat. This difference might lead to a better stability for the primary particles containing a small amount of MAA and, hence, more primary particles were generated during the particle nucleation period. Muroi ${ }^{32}$ investigated batch emulsion polymerization of ethyl acrylate in the presence of a small amount of AA or MAA and he found about $3-4 \%$ water-soluble oligomers in the aqueous phase. Greene ${ }^{6,7}$ studied semibatch emulsion copolymerization of styrene, butadiene, and a small amount of AA or MAA. His experimental data showed that distribution of AA and MAA in the three phases (water : surface layer of the particles: core of the particles) were $2: 3: 1$ and $1: 1: 1$, respectively. Thus, it can be concluded from these independent studies that in comparison with MAA a significant amount of AA may not be incorporated into the particles during polymerization.

Figure 4 shows the $\log \left(d_{\mathrm{p}}\right)-v s .-\log (t)$ data for the experiments containing $5 \%$ AA or $5 \%$ MAA. Again, the curve with circular data points and error bars represents the data for poly(butyl acrylate) latex particles containing no carboxylic monomers. The type of carboxylic monomers has an insignificant effect on the latex particle size at any time during the monomer addition period. The slopes of the $\log \left(d_{\mathrm{p}}\right)-v s \cdot-\log (t)$ data are 0.317 and 0.356 for the runs containing 5\% AA and 5\% MAA, respectively (see Table II). These data suggest that both carboxyl monomers are effective in promoting the latex stability during the monomer feed period. The particle size of the finished latex product is $561 \mathrm{~nm}$ for the run with no carboxylic monomers, $327 \mathrm{~nm}$ for the run with $5 \% \mathrm{AA}$, and $387 \mathrm{~nm}$ for the run with 5\% MAA. The particle size distributions of both the finished products 
containing carboxylic monomers are relatively narrow (see the $d_{\mathrm{w}} / d_{\mathrm{n}}$ data in Table II). Nevertheless, the $\zeta$ of the final particles containing $5 \%$ MAA $(-81 \mathrm{mV})$ is much higher than that containing $5 \%$ AA $(-53 \mathrm{mV})$ (see Table II). The $\zeta$ data suggest that the surface layer of the particles for the run with 5\% MAA should contain more negatively charged carboxyl groups, which is consistent with the experimental results of Ceska, ${ }^{19,20}$ Muroi, ${ }^{32}$ and Greene. ${ }^{6,7}$ Another possible explanation is that for the finished product incorporated with $5 \%$ AA the ionized polyelectrolyte in water can compress the electric double layer of the particles and, therefore, significantly reduce the $\zeta$ of the particles.

\section{Characterization}

The $\zeta$ of the final latex particles containing no carboxylic monomers, $5 \% \mathrm{AA}$, and 5\% MAA as a function of $[\mathrm{NaCl}]$ are shown in Figure 5 , in which $[\mathrm{NaCl}]$ is the concentration of $\mathrm{NaCl}$ and the negative sign of the ordinate simply represents that the particles carry negative charges. All the three $\zeta-v s-\log [\mathrm{NaCl}]$ curves show similar trends. The $\zeta$ of the final particles should depend on those parameters such as the particle size, ionic strength, distribution of sulfate and carboxyl groups in the particles, and fraction of the ionized carboxyl groups, etc. At a fixed $[\mathrm{NaCl}]$, the $\zeta$ of the final particles in the decreasing order is: BA emulsion polymer $>$ copolymer containing 5\% MAA>copolymer containing 5\% AA. The observed trend can be explained by the following factors. First, the latex particle size in the decreasing order is: BA emulsion polymer $>$ copolymer containing $5 \%$ MAA > copolymer containing 5\% AA. The larger the particle size is, the smaller is the total particle surface area required to be stabilized by $-\mathrm{SO}_{4}^{-}$end-groups. Thus, the larger the particle size is, the higher is the particle surface charge density and, hence, the higher is the $\zeta$ of the particles. Second, the latex particles containing $5 \%$ AA or MAA are covered by a relatively hydrophilic polymer layer that can shift the shear plane toward the bulk solution and, consequently, reduce the $\zeta$ of the particles. The degree of such a shift in the shear plane in the increasing order is: BA emulsion polymer $<$ copolymer containing 5\% MAA < copolymer containing $5 \%$ AA because, as will be shown below, the AA unit is preferably located near the particle surface layer. Finally, the amount of polyelectrolyte formed in water should follow the following order: BA emulsion polymer $<$ copolymer containing 5\% MAA $<$ copolymer containing 5\% AA. ${ }^{17}$ The ionized polyelectrolyte can compress the electric double layer of the particles and, thereby, cause the $\zeta$ of the particles to decrease. All these factors suggest that the latex particles containing no carboxylic monomers should have the highest $\zeta$.

Figure 5 also shows that the $\zeta$ of the particles first increases to a maximum and then decreases with an increase in $[\mathrm{NaCl}]$. For the particles containing no carboxylic monomers, it is very difficult to explain the observation that the $\zeta$ of the particles increases to a peak when $[\mathrm{NaCl}]$ is increased from $2 \times 10^{-4}$ to $1 \times 10^{-2} \mathrm{M}$. It is postulated that the increased $\zeta$ is caused by the limited flocculation process taking place during the sample preparation. The limited flocculation process can reduce the total particle surface area and thereby



Figure 5. The zeta potential of the final latex particles as a function of the $\mathrm{NaCl}$ concentration: $(\triangle) \mathrm{BA} / \mathrm{AA}(100 / 0) ;(\square) \mathrm{BA} / \mathrm{MAA}(95 / 5)$; (O) BA/AA $(95 / 5)$.

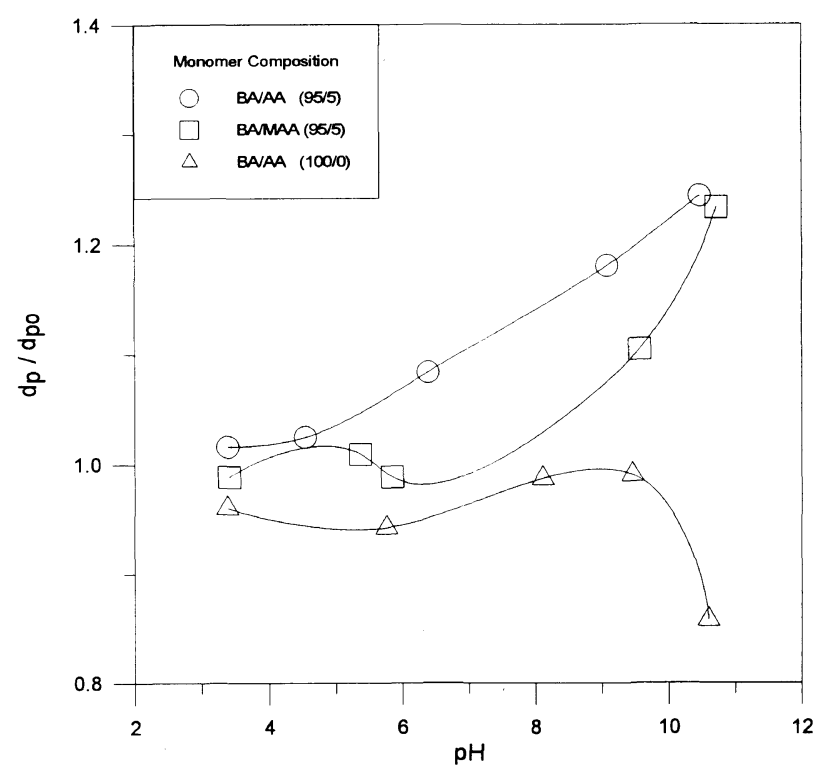

Figure 6. The $d_{\mathrm{p}} / d_{\mathrm{p} 0}$ data as a function of $\mathrm{pH}:(\triangle) \mathrm{BA} / \mathrm{AA}(100 / 0)$; ( $\square)$ BA/MAA $(95 / 5)$; (○) BA/AA $(95 / 5)$.

increase the particle surface charge density. For the particles containing $5 \%$ AA or $5 \%$ MAA, the maximal point can be explained by compression of the shear plane inward when $[\mathrm{NaCl}]$ is increased from $2 \times 10^{-4}$ to $1 \times 10^{-2} \mathrm{M} \cdot{ }^{33}$ On the other hand, the decreased $\zeta$ upon further increasing $[\mathrm{NaCl}]$ can be attributed to the increased ionic strength. It is also interesting to note that the $\zeta$ of the particles containing 5\% AA is less sensitive to the salt addition than that containing 5\% MAA. Thus, the finished latex product incorporated with $5 \%$ AA should be more stable toward the salt addition than that incorporated with 5\% MAA. This prediction will be further discussed later.

The particle swelling behavior for the finished latex products incorporated with no carboxylic monomers, $5 \% \mathrm{AA}$, and 5\% MAA is illustrated in Figure 6. As expected, the $d_{\mathbf{p}} / d_{\mathbf{p} 0}$ data for the latex sample containing 
no carboxylic monomers do not change very much below $\mathrm{pH}$ 9. The parameters $d_{\mathrm{p}}$ and $d_{\mathrm{p} 0}$ are the particle diameter measured in the particle swelling experiment and the particle diameter of the original latex product, respectively. The decreased $d_{\mathrm{p}} / d_{\mathrm{p} 0}$ above $\mathrm{pH} 9-10 \mathrm{can}$ be attributed to the excess sodium salt. ${ }^{34}$ On the other hand, the $d_{\mathrm{p}} / d_{\mathrm{p} 0}$ data for the sample containing $5 \% \mathrm{AA}$ or $5 \%$ MAA remain relatively constant before $\mathrm{pH} 5-6$ and, thereafter, the ratio $d_{\mathrm{p}} / d_{\mathrm{p} 0}$ increases rapidly with increasing $\mathrm{pH}$ because of the increased degree of neutralization of the carboxyl groups in the particles. Furthermore, the rate of change in $d_{\mathrm{p}} / d_{\mathrm{p} 0}$ with $\mathrm{pH}$ is faster for the sample containing 5\% AA than that for the sample containing 5\% MAA. This is probably due to the different distribution patterns of AA and MAA units in the particles. A significant proportion of the AA units incorporated into the emulsion polymer can be found near the surface layer of the particles. ${ }^{6,7}$

Figure 7 shows the $\zeta-v s .-\mathrm{pH}$ data for the finished latex products incorporated with no carboxyl monomers, 5\% AA, and 5\% MAA. The conductivity data of the latex samples as a function of $\mathrm{pH}$ are shown in Figure 8 and these data should reflect the ionic strength of the aqueous solution. Figure 7 shows that the $\zeta$ of the particles containing no carboxylic monomers is relatively insensitive to changes in $\mathrm{pH}$. The gradually increased $\zeta$ of the particles with $\mathrm{pH}$ is probably caused by the carboxyl groups derived from the hydrolysis of the sulfate end-groups and subsequent oxidation of the generated hydroxyl groups. ${ }^{35}$ On the other hand, the $\zeta$ data for both the carboxylated latices are $\mathrm{pH}$-dependent. For the sample with $5 \%$ AA, the $\zeta$ of the particles decreases with an increase in $\mathrm{pH}$ because of the shift of the shear plane toward the bulk solution. The $\zeta$ of the particles incorporated with 5\% MAA first increases to a maximum around $\mathrm{pH} 5$ because the increased ionization of the carboxyl groups with $\mathrm{pH}$ can cause an increase in the particle surface charge density. Another factor is that the conductivity of the sample is quite high below $\mathrm{pH} 4$ since the $\mathrm{H}^{+}$ion becomes more important in determining the ionic strength of the solution in comparison with $0.01 \mathrm{M}$ $\mathrm{NaCl}$ in this $\mathrm{pH}$ range (see Figure 8). The increased ionic strength with decreasing $\mathrm{pH}$ can compress the electric double layer of the particles and, hence, result in a decrease in the $\zeta$ of the particles. After the maximal point is reached, the $\zeta$ of the particles starts to decrease with an increase in $\mathrm{pH}$. This result can be explained by the fact that the particles are covered by a very hydrophilic polymer layer that can shift the shear plane toward the bulk solution and, consequently, reduce the $\zeta$ of the particles. Above $\mathrm{pH} \mathrm{10,} \mathrm{the} \mathrm{increased} \mathrm{conductivity} \mathrm{with}$ $\mathrm{pH}$ (see Figure 8) also can compress the electric double layer of the particles and, consequently, result in a decrease in the $\zeta$ of the particles. Furthermore, the increased particle size (i.e., the increased particle surface area) with $\mathrm{pH}$ also can cause a decrease in the particle surface charge density and thereby reduce the $\zeta$ of the particles.

The $\mathrm{pH}$ titration data for the dialyzed latex samples incorporated with no carboxylic monomers, $5 \% \mathrm{AA}$, and $5 \%$ MAA are shown in Figure 9. For comparison, a blank sample (water) was also included in this $\mathrm{pH}$ titration study. The $\mathrm{pH}$ curves for the blank sample and

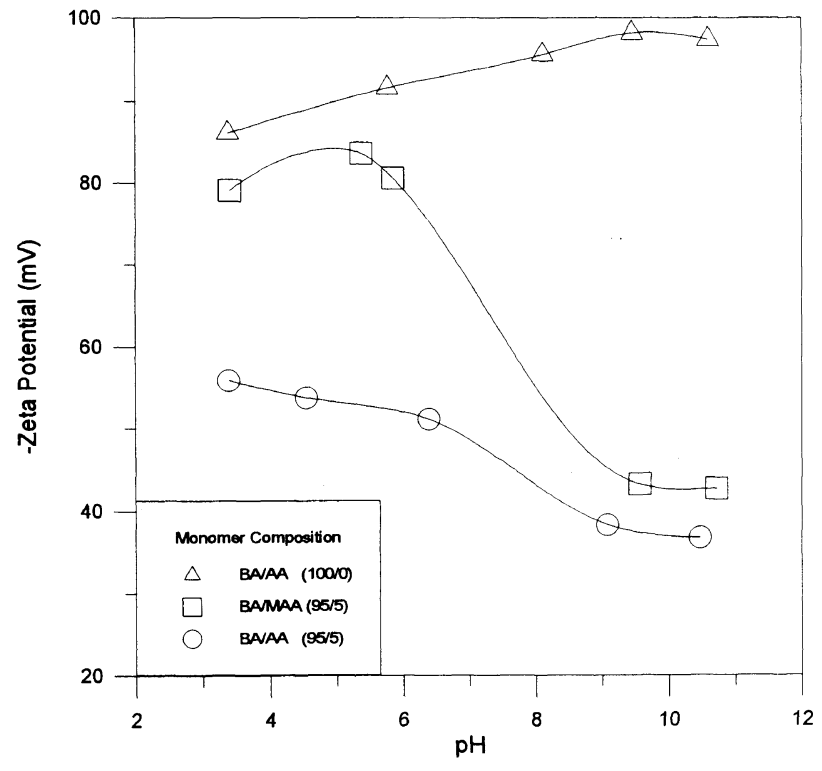

Figure 7. The zeta potential of the final latex particles as a function of $\mathrm{pH}:(\triangle) \mathrm{BA} / \mathrm{AA}(100 / 0)$; ( $\square) \mathrm{BA} / \mathrm{MAA}(95 / 5) ;(\bigcirc) \mathrm{BA} / \mathrm{AA}(95 / 5)$.

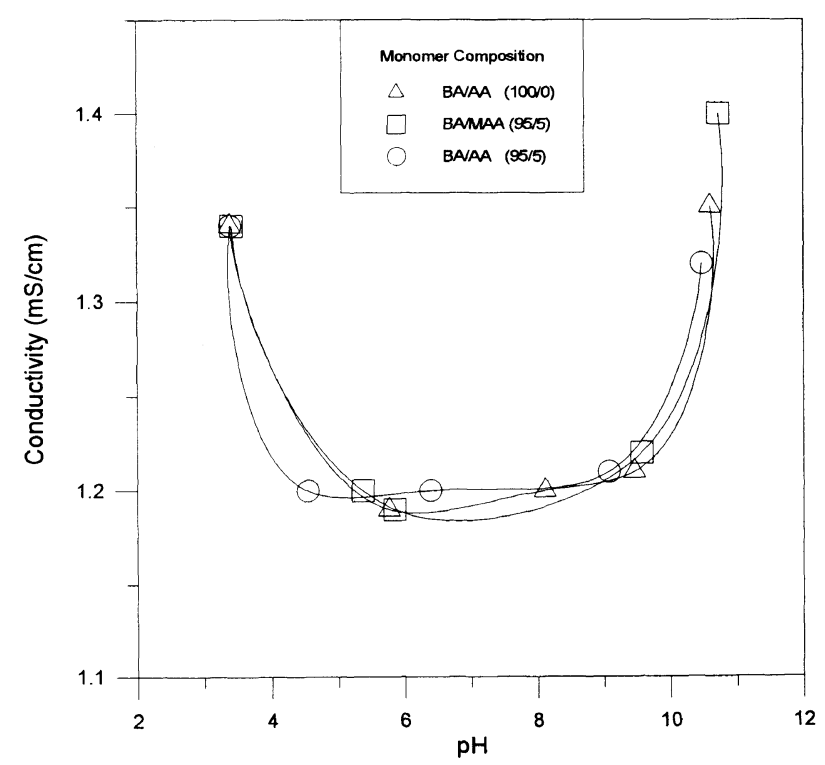

Figure 8. The conductivity of the finished latex products as a function of pH: $(\triangle)$ BA/AA $(100 / 0)$; ( $\square)$ BA/MAA $(95 / 5)$; ( $\bigcirc)$ BA/AA $(95 / 5)$.

the latex sample containing no carboxylic monomers are very sharp and they almost coincide with each other. On the other hand, the rate of change in $\mathrm{pH}$ with the titration process is slower for the sample with $5 \%$ AA or $5 \%$ MAA. At a common volume of the added $0.05 \mathrm{~N} \mathrm{NaOH}$ solution, the $\mathrm{pH}$ of the sample with $5 \% \mathrm{AA}$ is always lower than that with 5\% MAA. These data suggest that a significant proportion of the AA units is distributed near the particle surface layer, whereas the more hydrophobic MAA unit can be distributed more uniformly in the particles. This result is consistent with the literature. $^{6,7}$

Figure 10 shows the conductometric titration data for the dialyzed latex samples containing no carboxylic monomers, 5\% AA, and 5\% MAA. The conductivity of the sample containing no carboxylic monomers only decreases slightly with the conductometric titration process. On the other hand, the conductivity of both the 


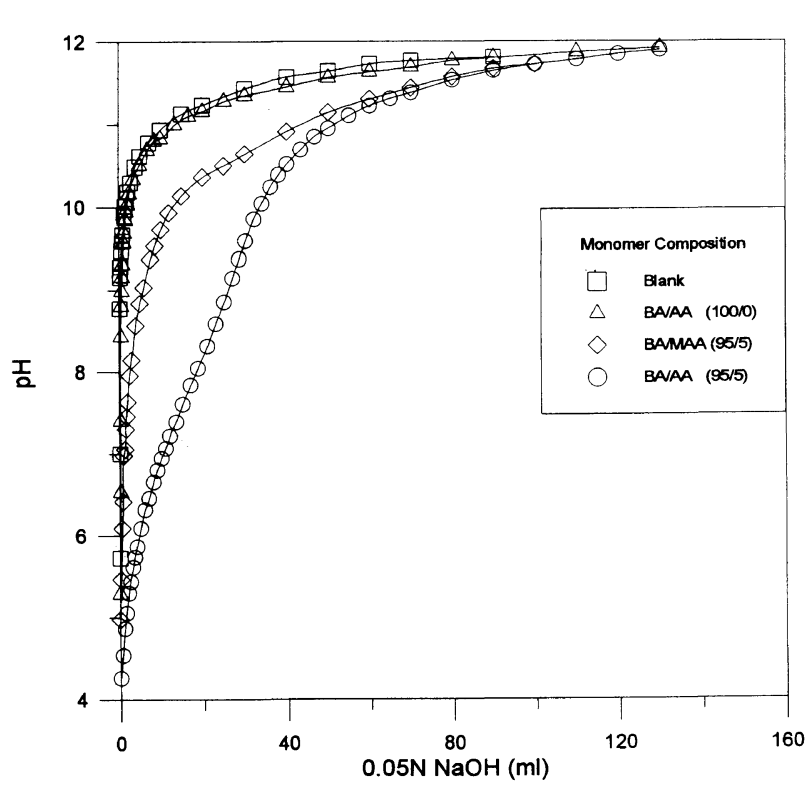

Figure 9. The $\mathrm{pH}$ titration data for the finished latex products: $(\square)$ blank (water); $(\triangle)$ BA/AA $(100 / 0) ;(\diamond)$ BA/MAA $(95 / 5) ;(\bigcirc)$ BA/AA $(95 / 5)$.

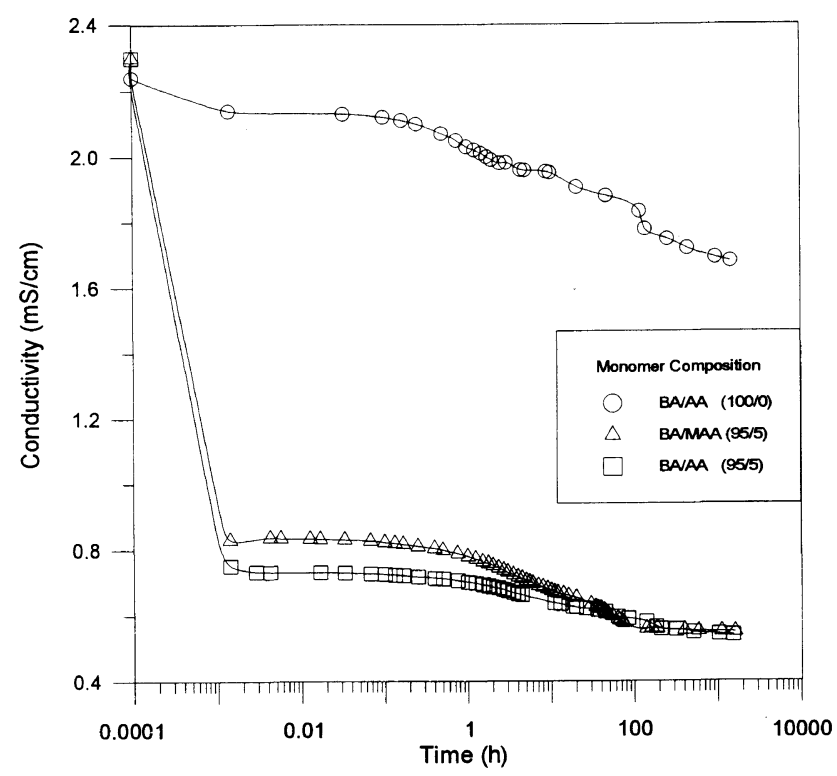

Figure 10. The conductometric titration data for the finished latex products: (O) BA/AA (100/0); ( $\triangle$ ) BA/MAA $(95 / 5)$; ( $\square)$ BA/AA $(95 / 5)$.

samples with 5\% AA and 5\% MAA decreases rapidly during the very early stage of titration (within $1 \mathrm{~min}$ ) and, thereafter, reaches the first plateau region $\left(10^{-3}-\right.$ $10^{\circ} \mathrm{h}$ ). After passing through the first plateau region, the conductivity decreases again $\left(10^{0}-10^{2} \mathrm{~h}\right)$ and finally reaches the second plateau region (greater than $10^{2} \mathrm{~h}$ ). The magnitude of the decreased conductivity between the starting point and the first plateau region is attributed to the carboxyl groups in the particle surface layer, whereas that between the first and the second plateau region can be attributed to the detectable carboxyl groups buried inside the particles. The latter conductometric titration should be limited by the diffusion process. Thus the ratio of the carboxyl groups in the particle surface layer to those in the core of the particles is estimated to be $5: 1$ and $8: 1$ for the

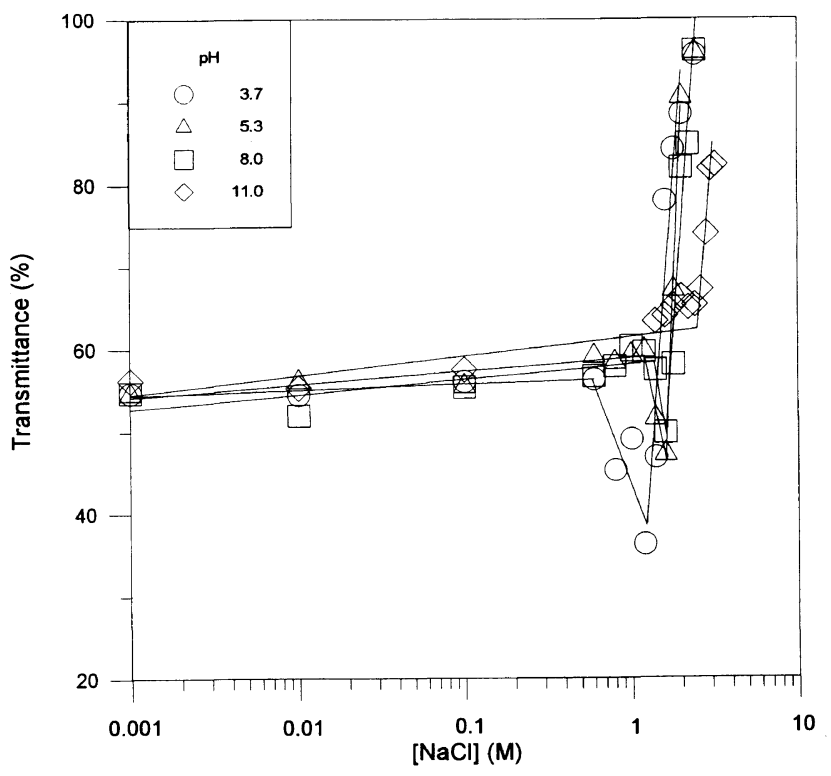

Figure 11. The transmittance data for the finished latex product containing $5 \%$ AA at various values of $\mathrm{pH}$ : $(\bigcirc) \mathrm{pH} 3.7 ;(\triangle) \mathrm{pH} 5.3$; ( $\square) \mathrm{pH} 8.0 ;(\diamond) \mathrm{pH} 11.0$.

latex sample incorporated with 5\% MAA and 5\% AA, respectively. These ratios are qualitatively consistent with the work of Greene, ${ }^{6,7}$ in which they are determined to be $1: 1$ and $3: 1$ for the semibatch reaction system using MAA and AA, respectively. This result, again, implies that the MAA unit can be distributed more uniformly in the particles as compared to the AA units. However, for the surfactant-free reaction system both the MAA and AA units seem to preferably remain near the particle surface layer in comparison with the system stabilized by conventional surfactants. Such a difference is probably related to the more hydrophobic particle surface associated with the surfactant-free system.

Figure 11 shows the transmittance- $v s .-\log [\mathrm{NaCl}]$ data for the latex sample incorporated with $5 \%$ AA at various values of $\mathrm{pH}$. The transmittance data for the sample at $\mathrm{pH}$ 3.7, for example, are maintained at a relatively constant level when $[\mathrm{NaCl}]$ is increased from 0.001 to $0.586 \mathrm{M}$. Subsequently, the transmittance starts to decrease rapidly to a minimum with increasing $[\mathrm{NaCl}]$ because of the aggregate formation. The point at which $[\mathrm{NaCl}]$ equal to $0.586 \mathrm{M}$ is thereby identified as the critical flocculation concentration (CFC). After the minimal point is reached, the transmittance increases sharply with increasing $[\mathrm{NaCl}]$ as larger flocs start to form and then precipitate under the influence of gravitational force. Thus the minimal point of the transmittance-vs.$\log [\mathrm{NaCl}]$ curve can be defined as the critical sedimentation concentration (CSC). It is interesting to note that the minimal point (CSC) becomes less significant when the $\mathrm{pH}$ of the sample is increased from 3.7 to 11.0. This trend is probably due to the enhanced chemical stability of the carboxylated latex with increasing $\mathrm{pH}$. The enhanced latex stability can retard the aggregate formation during the sample preparation. Thus the transmittance-vs. $-\log [\mathrm{NaCl}]$ curve only shows a shallow minimum as the sodium salt is continuously added to the sample. The transmittance- $v s .-\log [\mathrm{NaCl}]$ curve for the sample with 5\% MAA also exhibits similar trends. 


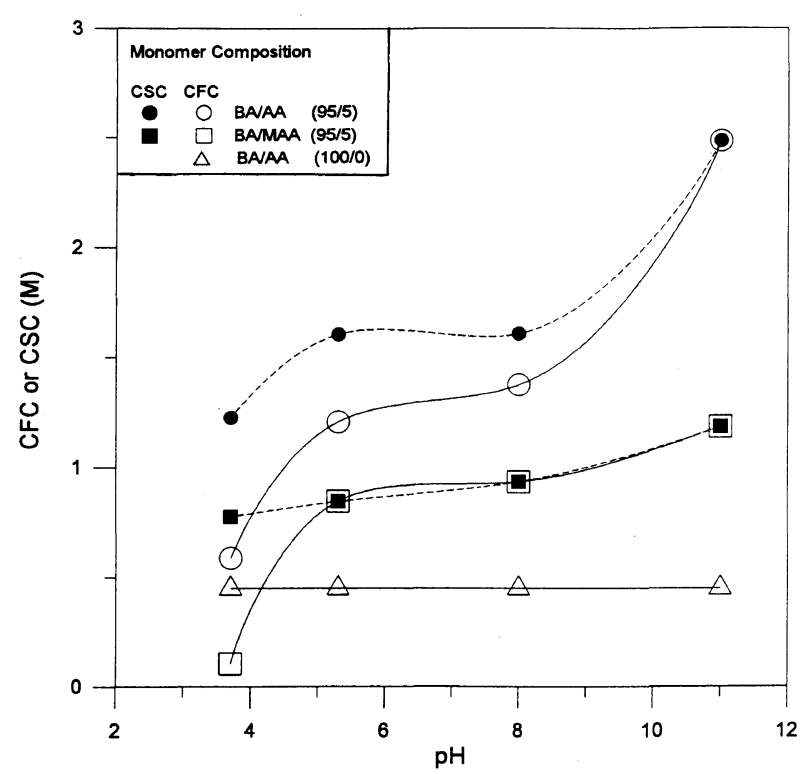

Figure 12. The critical flocculation or sedimentation concentration data for the finished latex products, CFC: (O) BA/AA $(95 / 5) ;(\square)$ BA/MAA $(95 / 5) ;(\triangle)$ BA/AA (100/0); CSC: (О) BA/AA $(95 / 5)$; BA/MAA $(95 / 5)$.

The CFC data for the samples incorporated with no carboxylic monomers, 5\% AA and 5\% MAA as a function of $\mathrm{pH}$ are shown in Figure 12. As expected, the CFC of the sample containing no carboxylic monomers is not sensitive to changes in $\mathrm{pH}$, whereas the $\mathrm{CFC}$ of both the carboxylated samples increases with an increase in $\mathrm{pH}$. At a constant $\mathrm{pH}$, the CFC for the sample with 5\% AA is higher than that for the sample with $5 \%$ MAA throughout the $\mathrm{pH}$ range. Thus, it can be concluded that incorporation of $5 \% \mathrm{AA}$ or $5 \%$ MAA into the emulsion polymers can greatly improve the chemical stability of the finished latex products, especially when the $\mathrm{pH}$ is high. Furthermore, the carboxylic monomer AA is more effective in promoting the chemical stability of the finished products as compared to MAA. These results support the above prediction based on the experimental data shown in Figure 5. Please note that the CFC of the latex particles containing 5\% MAA is lower than that of the particles containing no carboxylic monomers at the lowest $\mathrm{pH}$ (3.7), as shown in Figure 12. The reason for this observation is not clear at this point of time, but it might be related to the complicated interactions among the parameters such as the $\zeta$ of the particles, shift in the shear plane toward the bulk solution, and compression of the electric double layer of the particles, etc. For comparison, the CSC data for both the carboxylated samples are also included in Figure 12 (see the closed circular and square data points) and these CSC data also show similar trends.
Acknowledgment. The financial support from $\mathrm{Na}$ tional Science Council, Taiwan, Republic of China (NSC 85-2216-E-011-001) is gratefully acknowledged.

\section{REFERENCES}

1. P. Fram, G. T. Stewart, and A. J. Szlochtum, Ind. Eng. Chem., 47, 1000 (1955).

2. B. G. Elgood, E. V. Gulbekian, and D. Kinsler, J. Polym. Sci., $B, 2,257$ (1964).

3. R. A. Wessling, J. Appl. Polym. Sci., 12, 369 (1968).

4. H. Gerrens, J. Polym. Sci., C, 27, 77 (1969).

5. J. J. Krackeler and H. Naidus, J. Polym. Sci., C, 27, 207 (1969).

6. B. W. Greene, J. Colloid Interf. Sci., 43, 449 (1973).

7. B. W. Greene, J. Colloid Interf. Sci., 43, 462 (1973)

8. P. Bataille, B. T. Van, and Q. B. Pham, J. Appl. Polym. Sci., 22, 3145 (1978).

9. J. Snuparek, Jr., J. Appl. Polym. Sci., 24, 909 (1979).

10. J. Snuparek, Jr. and A. Tutalkova, J. Appl. Polym. Sci., 24, 915 (1979).

11. R. W. Novak, Adv. Org. Coat. Sci. Technol. Ser., 10, 54 (1988).

12. B. Li and B. W. Brooks, Polym. Int., 29, 41 (1992).

13. C. S. Chern and H. Hsu, J. Appl. Polym. Sci., 55, 571 (1995).

14. E. Unzueta and J. Forcada, Polymer, 36, 1045 (1995).

15. C. S. Chern, H. Hsu, and F. Y. Lin, J. Appl. Polym. Sci., in press.

16. C. S. Chern and C. H. Lin, Polym. J., 27, 1094 (1995).

17. C. S. Chern and F. Y. Lin, J. Macromol. Sci., Pure and Appl. Chem., accepted.

18. J. W. Goodwin, J. Hearn, C. C. Ho, and R. H. Ottewill, Br. Polym. J., 5, 347 (1973).

19. G. W. Ceska, J. Appl. Polym. Sci., 18, 427 (1974).

20. G. W. Ceska, J. Appl. Polym. Sci., 18, 2493 (1974).

21. S. Juang and I. M. Krieger, J. Polym. Sci., Polym. Chem. Ed., 14, 2089 (1976)

22. W. Y. Chiu and C. C. Shih, J. Appl. Polym. Sci., 31, 2117 (1986).

23. H. S. Chang and S. A. Chen, J. Polym. Sci., Polym. Chem. Ed., 26, 1207 (1988).

24. Z. Song and G. W. Poehlein, J. Colloid Interface Sci., 128, 486 (1989)

25. G. T. D. Shouldice, G. A. Vandezande, and A. Rudin, Eur. Polym. J., 30, 179 (1994).

26. R. M. Fitch, Br. Polym. J., 5, 467 (1973).

27. R. M. Fitch and C. H. Tsai, in "Polymer Colloids," R. M. Fitch, Ed., Plenum Press, New York, N.Y. 1971, pp 73-102.

28. F. V. Loncar, Jr., Ph.D. Dissertation in Polymer Science and Engineering, Lehigh University, Bethlehem, PA, 1985.

29. R. Buscall and T. Corner, in "Emulsion Polymers and Emulsion Polymerization," D. R. Basset and A. E. Hamielec, Ed., ACS Symposia Series 165, American Chemical Society, Washington, D.C., 1981, pp 157-169.

30. B. V. Derjaguin and L. Landau, Acta Physicochim. URSS, 14, 633 (1941).

31. E. J. W. Verwey and J. Th. G. Overbeek, "Theory of the Stability of Lyophobic Colloids," Elsevier, Amsterdam, 1948.

32. S. Muroi, J. Appl. Polym. Sci., 10, 713 (1966).

33. F. J. de las Nieves, E. S. Daniels, and M. S. El-Aasser, Collids Surfaces, 60, 107 (1991).

34. D. R. Bassett, E. J. Derderian, J. E. Johnston, and T. B. MacRury, in "Emulsion Polymers and Emulsion Polymerization," D. R. Basset and A. E. Hamielec, Ed., ACS Symposia Series 165, American Chemical Society, Washington, D.C., 1981, pp 263278.

35. X. Z. Kong, C. Pichot, and J. Guillot, Colloid Polym. Sci., 265, 791 (1987). 